Murdoch, G.P., C. M. Gitro, T. T. Lindley, and V. N. Mahale, 2019: Identifying Plume Mode via WSR-88D Observations of Wildland Fire Convective Plumes and Proposed Tactical Decision Support Applications. J. Operational Meteor., 7 (11), 153-163, doi: https://doi.org/10.15191/nwajom.2019.0711

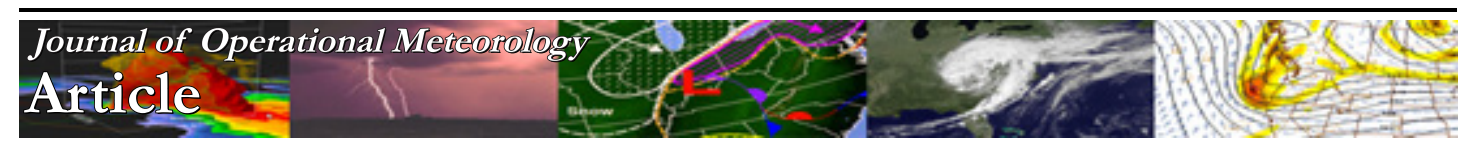

\title{
Identifying Plume Mode via WSR-88D Observations of Wildland Fire Convective Plumes and Proposed Tactical Decision Support Applications
}

\author{
GREGORY P. MURDOCH \\ NOAA/National Weather Service, Midland, TX \\ CHRISTOPHER M. GITRO \\ NOAA/National Weather Service, Duluth, MN \\ T. TODD LINDLEY AND VIVEK N. MAHALE \\ NOAA/National Weather Service, Norman, OK
}

(Manuscript received 29 November 2018; review completed 14 March 2019)

\begin{abstract}
To date, the use of Doppler radar (WSR-88D) in wildland fire operations has been limited, with tactical applications focused on analyzing ambient atmospheric features. This paper presents geographically diverse analysis of radar-observed wildland fire convective plumes to determine indicators of plume mode for tactical decision support. Through the visualization of buoyancy via thermal bubbles and vertical plumes, plume mode is revealed via WSR-88D interrogation of three Southern Great Plains grass/shrub fires and two timber fires in Texas and California. Analogous to thunderstorm convective modes, past research has identified two distinct plume modes of wildland fire: multicell and intense convective plume. Multicell plume mode is characterized by a series of shallow discrete cells that move away from the fire's main buoyancy source, with successive cells rising, expanding, and replacing cells from the updraft source. This process, known as the thermal bubble concept, occurs most notably in strong vertical wind profile environments with a strong advection component. These cells or thermal bubbles are observed via WSR-88D data for three Southern Great Plains cases. Intense convective plumes are observed to be vertical with the low-level reflectivity maximum and maximum echo top juxtaposed and occurrence is confined to weak wind environments; these plume structures are identified in the two timber fire cases. An important WSR-88D signature, the back-sheared convective plume (hereafter BSCP), is identified in terms of transverse vortices and vortex rings, which may imply enhanced combustion rates due to increased turbulent mixing. Determination of plume convective mode via radar offers meteorologists the ability to detect changes in plume mode and to provide important tactical decision support information about fire behavior.
\end{abstract}

\section{Introduction}

Fire behavior is governed by the type and state of fuels consumed, the topography, and ambient atmospheric conditions (Bradshaw et al. 1983). Plume mode, analogous to thunderstorm convective mode, is determined by buoyancy and ambient wind, and is indicative of certain fire behavioral characteristics. A series of studies (Kiefer et al. 2008, 2009; hereafter
K08 and K09, respectively) showed that for forest fires, variations in buoyancy and the mean layer wind determined primary plume mode as either multicell or intense convective plume. Additional subsets exist for both modes. Multicell plumes (K08) are characterized by individual elements resembling thermal bubbles, elements generated due to buoyancy and increased combustion that rise and expand (Mphale et al. 2007). The intense convective plume mode is characterized 
by a buoyancy-driven and vertically oriented updraft associated with inflow and outflow winds that spread the fire erratically (Banta et al. 1992). The basic premise behind a convective plume, as observed on the Weather Surveillance Radar-1988 Doppler (WSR-88D, Crum and Alberty, 1993) is that heat flux increases combustion, and as resultant buoyant forces accelerate upward, pyrometeors (McCarthy et al. 2019) are lofted higher in the plume (Jones and Christopher 2010). This provides an indirect estimate of the general intensity of a fire by the magnitude of returned reflectivity. McCarthy (2019) emphasizes that to understand a radar's depiction of a plume it is important to know the properties and distribution of pyrogenic scatterers. The particle size distribution of the pyroconvective plumes has a wide spectrum ranging from ash $(2 \mu \mathrm{m}$ to $1 \mathrm{~mm}$ in diameter) to large vegetation (on the order of centimeters in diameter to even larger) (McCarthy et al. 2019). The diversity of sizes and shapes results in a mixture of both Rayleigh and Mie scatterers within the radar sampling volume and a significant reduction of correlation coefficient (CC), especially due to Mie scatterers (Kumjian 2013).

Recent innovations in National Weather Service (NWS) fire weather operations have included tactical fire notifications of new wildfire ignitions derived from remote sensing tools such as Geostationary Orbiting Environmental Satellites (GOES) (Lindley et al. 2016). In a future warning paradigm, such notifications may constitute fire-specific warnings and communicate actionable tactical information with respect to firescale intelligence additionally derived from radar (Lindley et al. 2018). The WSR-88D has proven capable of providing useful tactical observations of convective plumes (Rogers et al. 1997), as well as wind shift interactions associated with near-surface boundaries including cold fronts (Lindley et al. 2006) and thunderstorm outflow (Potter and Hernandez 2017) that result in fire-site changes in wind speed and direction. Wind shifts are often times detrimental to firefighting efforts and continue to be a leading contributor to firefighter fatalities (Arizona State Fire Department 2013). Additionally, the WSR-88D has been used to detect horizontal convective rolls that are coincident with a fire, resulting in short-term increases in buoyant forces, strengthening convective plumes, and an increase in non-steady state fire behavior (Murdoch et al. 2016). WSR-88D and Doppler data were used as a tool to provide convective plume height and trajectory information, which has proven valuable for air quality and transportation impacts (Ashley et al. 2015). Forecasters leveraging meteorological remote sensing tools, such as radar and satellite data, possess a unique capability to serve as "eyes and ears" for firefighters in the field. Therefore, as the fire weather support provided by NWS forecast offices continues to shift towards improved impact-based decisionsupport services (IDSS; NWS 2018), it will become increasingly important for forecasters to relay critical information on high impact fires using remotely sensed fire-atmosphere interactions (Lareau et al. 2018) to key decision makers and first responders.

Unfortunately, conceptual models for applying WSR-88D analysis to operational tactical support for wildland fire are lacking. Analogous to severe weather signatures observed through radar analysis of deep moist convection, we also propose benefits of radar analysis for pyroconvective processes associated with wildland fire. Recently, McCarthy et al. (2019) noted the importance of using the temporal advantages of radar to aid in linking plumes and the atmosphere in operational settings. Viewing the convective plume as an atmospheric process of convective continuity provides radar operators context in which to analyze plume morphology. This paper investigates Doppler radar-based observations of convective plumes with the purpose of documenting characteristics of plumes modeled in research and observed in the field, promoting increased tactical awareness for the advantage of firefighter and public safety. This paper can be viewed as a first step in preparation for possible paradigm changes in tactical fire operations for the NWS. Through radar analysis of the 350 Complex [5 April 2016; $233 \mathrm{~km}^{2}$ (57 $576 \mathrm{ac}$ )], the Buffalo Fire [18 February 2016; $73 \mathrm{~km}^{2}$ (18 039 ac)] in northwestern Oklahoma, the Jackson County Fire in southwestern Oklahoma [1 March 2017; $20 \mathrm{~km}^{2}$ (4,942 ac)], the Cedar Fire in south-central California [19 August 2016; 110 $\mathrm{km}^{2}$ (27 $182 \mathrm{ac}$ )], and the Hidden Pines Fire in central Texas [14 October 2015; $19 \mathrm{~km}^{2}$ (4,795 ac); Fig. 1, Table 1], it will be shown that plume mode can be determined operationally in agreement with Mphale et al. (2007), $\mathrm{K} 08, \mathrm{~K} 09$, and that basic tactical-level conclusions can be made about the atmospheric environment and on fire behavior. These conceptual models have led to the observation of thermal bubbles, transverse vortices, and BSCP through the WSR-88D network. 


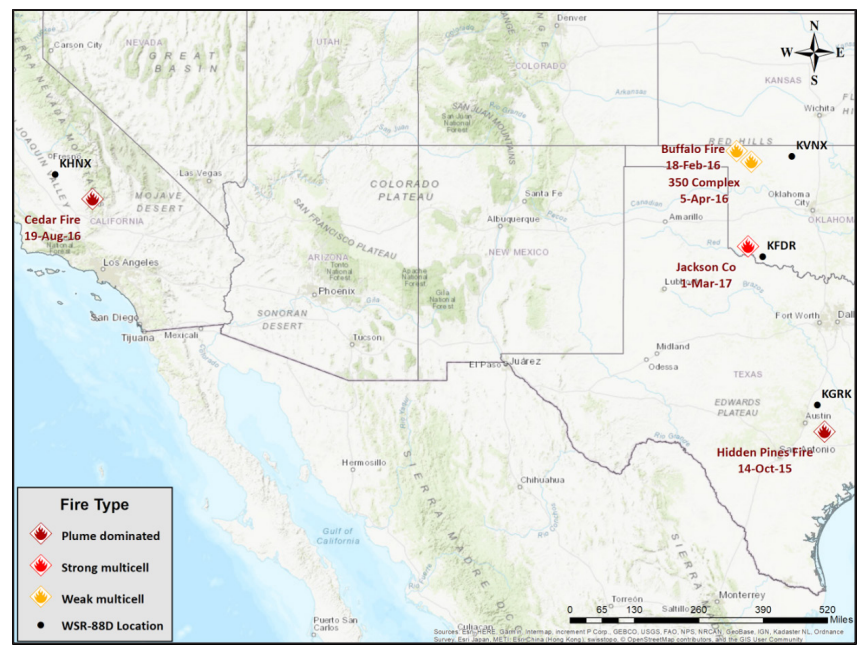

Figure 1. Regional map showing fire locations and fire mode along with corresponding WSR-88D locations used for this study. Click image for an external version; this applies to all figures and tables hereafter.

\section{Data and methods}

In this study, convective plumes from five fires are analyzed using WSR-88D data from Vance Air Force Base, Oklahoma (VNX); Frederick, Oklahoma (FDR); Hanford, California (HNX); and Ft. Hood, Texas (GRK). In each case Volume Coverage Pattern (VCP) 32 (NOAA 2017) was used. The five fires examined include three warm season fires, two of which (Cedar and Hidden Pines Fires) were in timber understory fuels (fuel model TU5 timber understory, Scott and Burgan, 2005), with the other (350 Complex) in grass fuel regimes (fuel model GR3 grass fuel, Scott and Burgan, 2005). Meanwhile, both the Buffalo and Jackson County Fires were cool season fires in grass/shrub fuels (fuel model GR3 grass fuel, Scott and Burgan, 2005). In our analysis we distinguished between weak and strong multicell plumes by comparing the dimension of the thermal bubbles and the horizontal distance downstream with respect to time. An analysis of the horizontal distances between the lowest level reflectivity maxima and the echo top maxima for multicell plumes and intense convective plumes was used to distinguish plume modes. Level II data (NOAA 2018) were downloaded from the NEXRAD Amazon Web Services and examined with the GRLevel2 program produced by Gibson Ridge Software, LLC including: maximum echo top and base reflectivity (dBZ). Volumetric displays were created to illustrate plume structure and identify plume features. As a result of the time needed for the Radar Product Generator (RPG; WDTD 2019)
Table 1. Summary of fire and radar information used for this study.

\begin{tabular}{|c|c|c|c|c|}
\hline Fire Name & Date & Size & State & WSR-88D \\
\hline 350 Complex & 5 Feb 2016 & $\begin{array}{c}233-\mathrm{km}^{2} \\
(57,576-\mathrm{ac})\end{array}$ & NW Oklahoma & $\begin{array}{c}\text { Vance AFB } \\
\text { (KVNX) }\end{array}$ \\
\hline Buffalo Fire & $18 \mathrm{Feb} 2016$ & $\begin{array}{c}73-\mathrm{km}^{2} \\
(18,039-\mathrm{ac})\end{array}$ & NW Oklahoma & $\begin{array}{c}\text { Vance AFB } \\
\text { (KVNX) }\end{array}$ \\
\hline Jackson County & 1 Mar 2017 & $\begin{array}{c}20-\mathrm{km}^{2} \\
(4,942-\mathrm{ac})\end{array}$ & SW Oklahoma & $\begin{array}{c}\text { Frederick } \\
\text { (KFDR) }\end{array}$ \\
\hline Cedar Fire & 19 Aug 2016 & $\begin{array}{c}110-\mathrm{km}^{2} \\
(27,182-\mathrm{ac})\end{array}$ & $\begin{array}{c}\text { South-central } \\
\text { California }\end{array}$ & $\begin{array}{c}\text { Hanford } \\
\text { (KHNX) }\end{array}$ \\
\hline Hidden Pines & 14 Oct 2015 & $\begin{array}{c}19-\mathrm{km}^{2} \\
(4,795-\mathrm{ac})\end{array}$ & Central Texas & $\begin{array}{c}\text { Ft. Hood } \\
\text { (KGRK) }\end{array}$ \\
\hline
\end{tabular}

to create derived products such as maximum echo tops, there is almost a 9-min difference between the base product (reflectivity) time stamp and maximum echo top time stamp. The GR2 program makes a distinction between "volume coverage start time" to reflect base product generation time, and "product time" to signify the time in which the derived product was produced by the RPG. These time differences are included in our analysis where maximum echo top data were used. It is important to be aware of these time differences because the horizontal spatial difference between the low-level reflectivity maxima and the echo top maxima can be exaggerated.

\section{Multicell radar analysis}

The multicell plume mode is described as "a series of discrete vertical protrusions of soot and smoke with a substantial lateral component of motion" (K08). This plume mode represents what is commonly known as a wind-driven fire (Rothermel 1991). Multicell mode can be broken down further into the strong and weak multicell, distinguished by cells that can develop vertically through the mixed layer (Stull 1988) from those that do not. Weak multicell mode is characterized by velocity couplets that deepen as distance increases from the fire, and under strong surface winds and increasing wind with height the strongest vertical velocities are found as far downwind as 15-20 km (K09). The thermal bubble conceptual model is an indication of energy released (Mphale et al. 2007), which indirectly highlights the upward acceleration of buoyant forces within the plume (Fig. 2), agreeing with the K08 multicell mode. By observing changes in the reflectivity data and the plume height relative to the lowlevel reflectivity maxima and cellular characteristics, changes in a fire's updraft can be inferred. To be clear, 


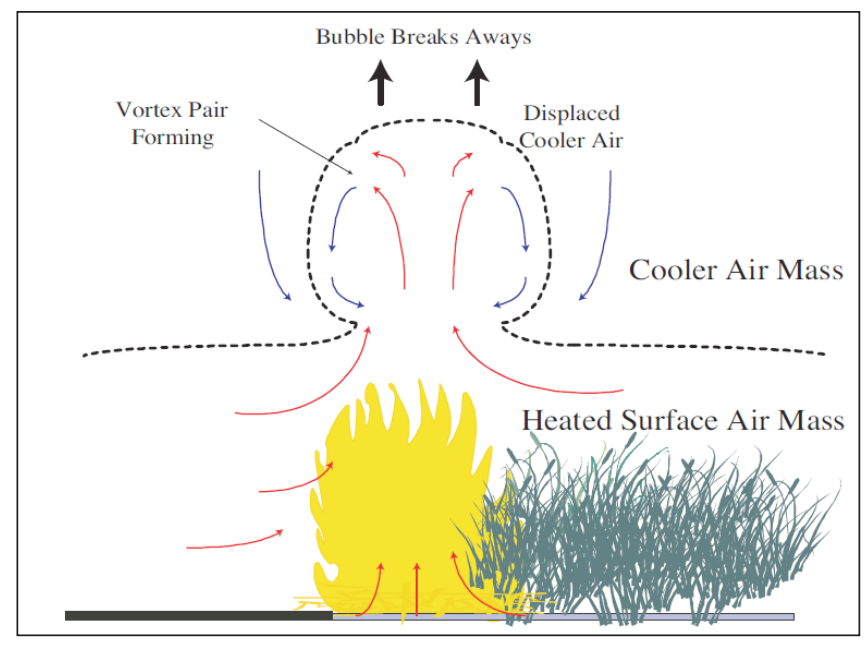

Figure 2. Conceptual illustration of thermal bubble formation, adopted from Mphale et al. 2007 (their Fig. 2).

weak and strong multicell plumes refer to the cellularity, not the intensity, of a fire; a high intensity wind-driven fire will generally exhibit a weak multicell plume.

\section{a. WSR-88D identification of multicells}

Recently, Doppler lidar observations of the El Portal Fire in California (Lareau and Clements 2017; hereafter LC17) confirmed K09 results that individual "convective elements" can be spatially and temporally followed downstream (Fig. 3a). Mobile X-Pol Radar (McCarthy et al. 2018) used high temporal resolution range height data to capture individual "puffs" transporting an increased amount of pyrometeors (Fig. $3 b)$. It is important to note that lidar and WSR-88D are detecting different scatterers. Lidar detects smoke aerosols (diameters less than one $\mu \mathrm{m}$ ) whereas WSR$88 \mathrm{D}$ detects the larger pyrometeors (diameters $>100 \mu \mathrm{m}$; Jones and Christopher 2010). The advantages of using portable, high resolution temporal and spatial radars are obvious; however, the challenge for operational fire weather forecasters is to analyze convective plumes using the available fixed platforms of national network radars with less temporal and spatial resolution.

In the advective wind environment of the typical plains grass fires, positively buoyant air over a fire is transported away from the heat source setting up a plume geometry that is tilted downwind in the vertical. Likewise, the maximum echo top of the convective plume is displaced downwind from the buoyancy source as shown in the Buffalo Fire case (Fig. 4a). The well-defined thermal bubbles in the Jackson County

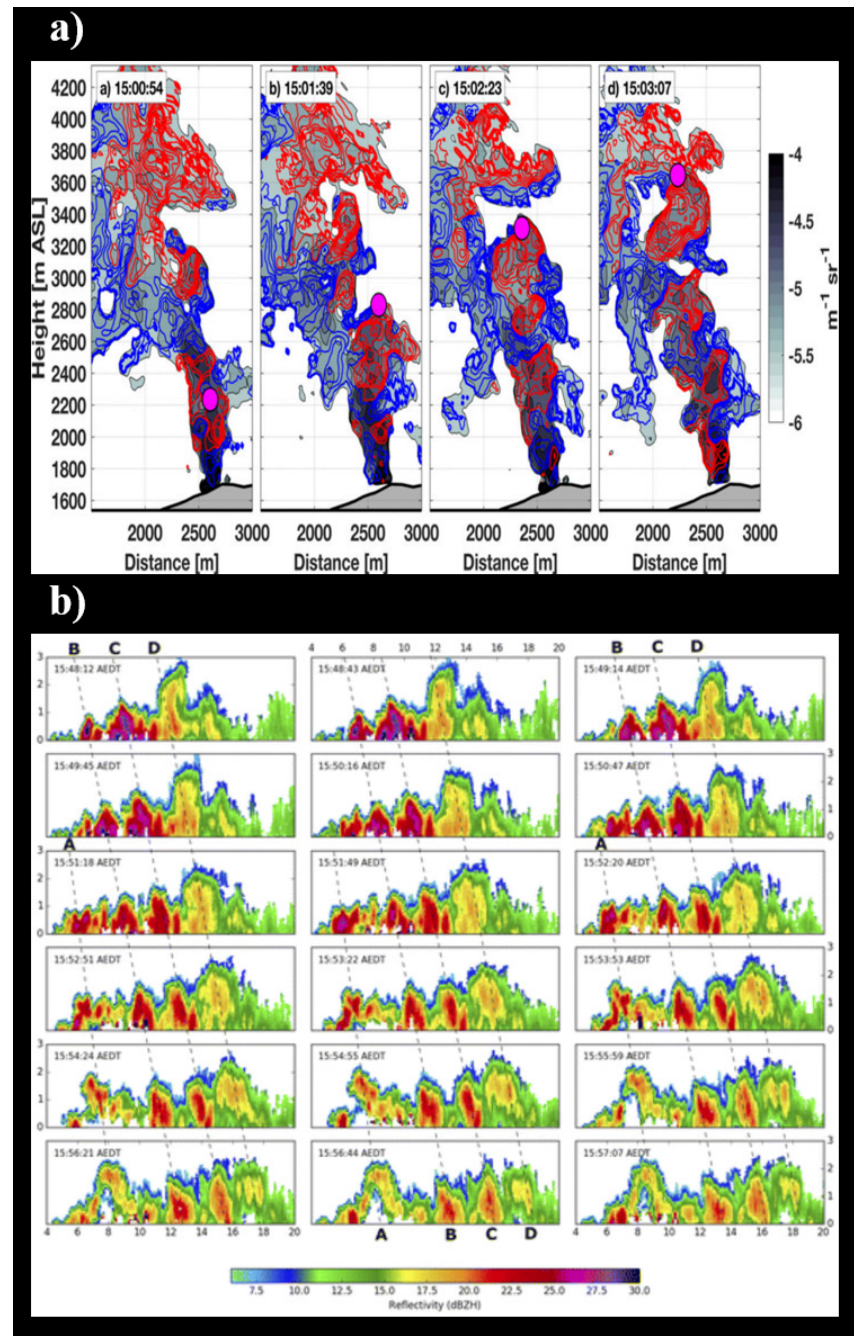

Figure 3. (a) Time height series showing that convective elements are tracked in Doppler lidar data and the horizontal vortex on the downwind side of the plume for the El Portal Fire. Image adopted from LC17, their Fig. 6. (b) A range height time series of convective plume elements of the Dereel Fire using X-Pol radar showing plume evolution. Image adopted from McCarthy et al. 2018, their Fig. 3.

Fire (Fig. 5) are indicative of a strong multicell plume mode in that within the first 20 minutes of detection by the WSR-88D, the first thermal bubble is $13 \mathrm{~km}$ downstream with a $4.1 \mathrm{~km}$ width along the downstream component. In comparison, the less defined, more continuous and elongated thermal bubbles of the 350 Complex in northwestern Oklahoma (Fig. 6) are indicative of the weak multicell plume mode, and within 20 minutes of detection the first thermal bubble was $29.6 \mathrm{~km}$ downstream with a width of $10.2 \mathrm{~km}$ along the downstream component. These differences were 


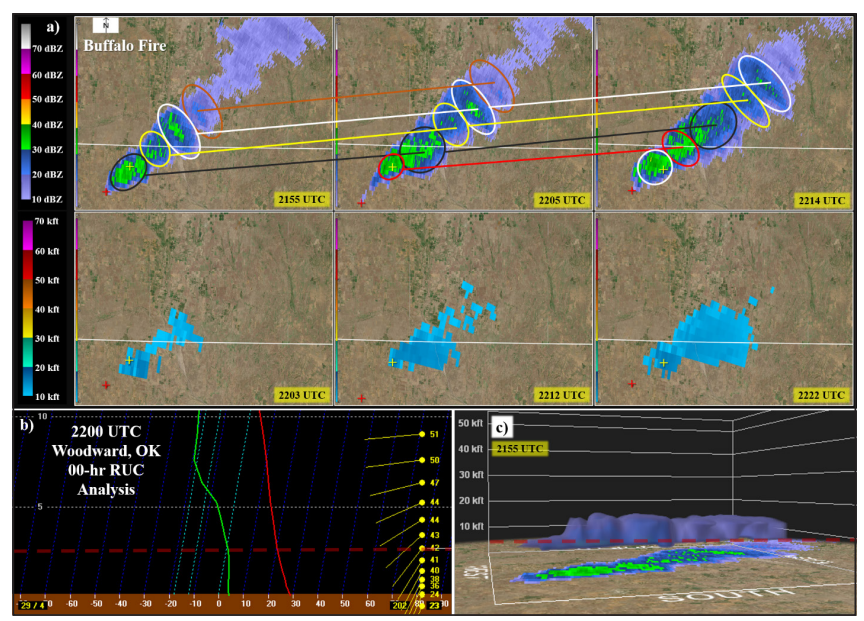

Figure 4. KVNX (a) base reflectivity (dBZ; valid at 2155, 2205, and 2214 UTC) and maximum echo top (kft; valid at 2203, 2212, and 2202 UTC) for the Buffalo Fire in northwestern Oklahoma on 18 February 2016. Red crosses (max reflectivity, near updraft source) and yellow crosses (max echo top) are displaced from one another, highlighting how the maximum echo top is typically displaced downwind from the lowlevel reflectivity maxima (red cross). (b) 00-hr RUC sounding analysis for Woodward, Oklahoma valid at 2200 UTC 18 February 2016, where solid red trace shows environmental temperature and solid green trace depicts environmental dewpoint, with wind barbs (kt) and digital readout displayed on the far right in yellow. White horizontal dashed lines with numeric values represent vertical height in kft. (c) Volumetric radar display from KVNX at 2155 UTC. Red dashed line on (b) and (c) represents approximate depth of convective boundary layer as inferred from the forecast sounding.

attributed to advection within the stronger ambient vertical wind environments for the Buffalo Fire and the 350 Complex and deeper convective boundary layers as seen in the proximity soundings (Fig. $4 b-c, 6 b-c$, respectively).

\section{b. Environmental conditions and tactical implications}

Incorporating the thermal bubble concept along with plume mode provides a framework for making determinations about fire character. Recognition of the thermal bubble is an immediate post-indicator of buoyancy from fuel consumption; it should be stressed that the thermal bubble itself is not necessarily an indication of dangerous fire behavior. Finney and McAllister (2018) noted that bubble frequency is related

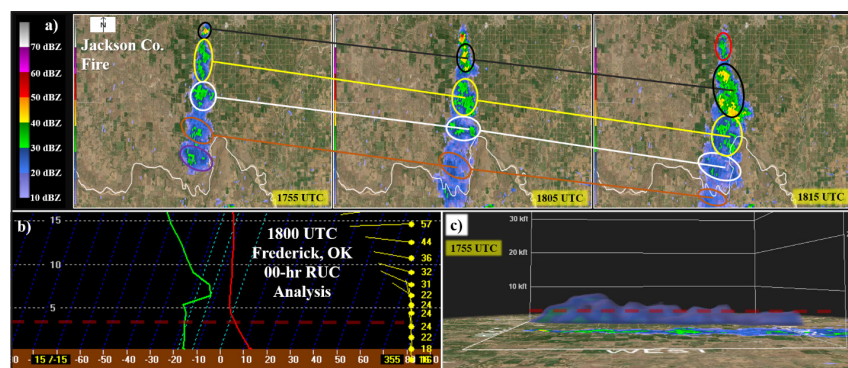

Figure 5. KVNX (a) base reflectivity (dBZ; valid at 1755, 1805, and 1815 UTC) for the Jackson County, Oklahoma fire on 1 March 2017. (b) 00-hr RUC sounding analysis for Frederick, Oklahoma valid at 1800 UTC 1 March 2017, where solid red trace shows environmental temperature and solid green trace depicts environmental dewpoint, with wind barbs $(\mathrm{kt})$ and digital readout displayed on the far right in yellow. White horizontal dashed lines with numeric values represent vertical height in $\mathrm{kft}$. (c) Volumetric radar display from KVNX at 2155 UTC. Red dashed line on (b) and (c) represents approximate depth of convective boundary layer as inferred from the forecast sounding.

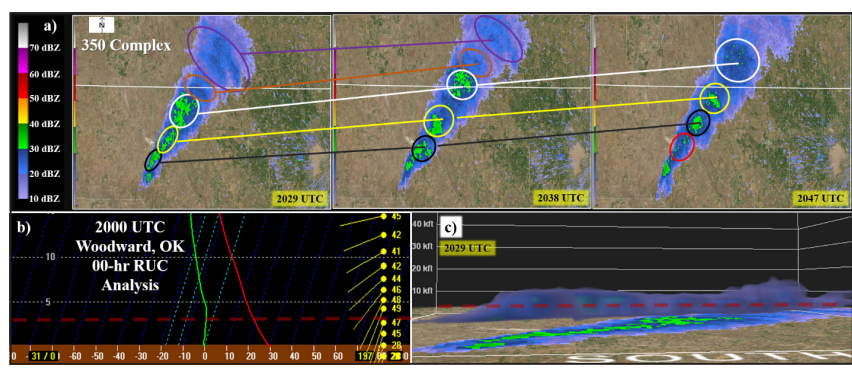

Figure 6. KVNX (a) base reflectivity (dBZ; valid at 2029, 2038, and 2047 UTC) for the 350 Complex Fire in northwestern Oklahoma on 5 April 2016. (b) 00hr RUC sounding analysis for Woodward, Oklahoma valid at 2000 UTC 5 April 2016, where solid red trace shows environmental temperature and solid green trace depicts environmental dewpoint, with wind barbs $(\mathrm{kt})$ and digital readout displayed on the far right in yellow. White horizontal dashed lines with numeric values represent vertical height in $\mathrm{kft}$. (c) Volumetric radar display from KVNX at 2155 UTC. Red dashed line on (b) and (c) represents approximate depth of convective boundary layer as inferred from the forecast sounding.

to fire size or diameter. The identification of a persistent series of thermal bubbles in radar data is an indicator of a quasi-steady state fire and subsequent changes in height, size and frequency of thermal bubbles are an indication of a change in plume mode and fire character 
including intensity, which can be considered important tactical information. A well-documented change in fire behavior associated with increased intensity is the transition from surface fire to crown fire. This transition in burn character can occur in either timber or brush fuel types, and is key intelligence for firefighter decision support (Werth et al. 2016). In grass and shrub fuels, fire intensity is limited by the amount of energy that can be released, though a relatively lower height of the plume's maximum top may be counterintuitive. The lower the plume's maximum height and the farther displaced downstream from the low-level reflectivity maximum may be indications of increased wind and therefore increased spread rates. It is noted that changes in fuel type, fire behavior, topography, and firefighting tactics could drastically change spread rates.

K09 emphasizes that the ability to discern different multicell fire modes is of tactical importance in the wildland fire environment. Cells in the strong multicell case are capable of mixing air that has stronger winds and low relative humidity aloft to the surface, thereby increasing the potential for non-steady state fire behavior. Strong multicell updrafts are deeper and loft pyrometeors higher than the weak multicell updrafts. This is important because a way for a fire to increase its rate of spread is by spotting, in which the fire plume lofts pyrometeors downwind, thus potentially igniting new fires (Werth et al. 2016). Spotting is related in terms of distance, long or short, from the fire and in terms of pyrometeor size and density (Werth et al. 2016). Cheney and Bary (1969) observed that most spotting on wildfires occurred within a "fan-shaped" zone of $9^{\circ}$ either side of the "primary wind." It is hypothesized that pyrometeors in strong multicell plumes are lofted to a height such that they can be extinguished before returning to the surface fuels, suggesting that the greatest spotting potential is generally with weak multicell cases. There are exceptions, including resinous fuels in which strong multicell plumes could result in greater spotting distances (Sardoy et al. 2007). Pyrometeors and their height within a plume are not the only consideration, the receptiveness of the fuel bed in which the pyrometeors land is important. Links between plume mode, plume geometry, pyrometeors, and spotting distances need further investigation.

\section{Intense convective plume}

During the typical western United States summer fire season, weaker winds aloft favor vertically erect convective plumes as compared to the more laterally displaced plumes associated with stronger wind environments seen on the Great Plains. Weaker winds aloft support longer plume residence time over a fire and less entrainment, and thus greater energy release from timbered fuel regimes (K08). Therefore, the convective plumes often reach much greater vertical depths, and are driven by circulations focused around the vertical axis of the fire's buoyant plume, and the maximum plume height is typically co-located, or vertically stacked with reflectivity maxima in the lower levels of the atmosphere. The intense convective plume mode is associated with the more commonly known plume-dominated fire (Rothermel 1991).

The visual appearance of a convective plume can be an indicator of an organizing updraft. Haines and Smith (1987) and Forthofer and Goodrick (2011) showed that the "boiling appearance" on the upwind side of an updraft is a visualization of buoyancy-induced transverse vortices, and Clements et al. (2018) and Lareau and Clements $(2016,2017)$ documented transverse vortices on the downwind side of other plumes using Doppler lidar, an important observation because Haines and Smith (1987) indicated that turbulent mixing was thought to obscure the downwind portion of the vortex ring. Transverse vortices occur on a range of scales (Werth et al. 2016) and collectively can form a transient vortex ring. Turbulence has been shown to be key in convective models as a means of increasing combustion (Linn et al. 2002). Convective plume scale transverse vortices are not only the visual representation of buoyancy-generated vorticity but also are an indication of turbulence and thus increased combustion rates ( $\mathrm{S}$. Goodrick 2018, personal communication).

Werth et al. (2016) noted that individual "turrets" (thermal bubbles) within a convective plume could move upwind. The continuity of the updraft is supported by low-level inflow and upper-level outflow or divergence, recently documented with Doppler lidar observations of the El Portal fire (LC17). A back-sheared anvil of severe deep moist convection is an indicator of upperlevel divergence (Glickman 2000) and updraft strength. We have identified an analogous BSCP and it is our supposition that the presence of such a feature is an indication of plume organization, including divergence and updraft strength. 


\section{a. WSR-88D analysis of intense convective plume mode}

WSR-88D observations of the Cedar and Hidden Pines Fires (Fig. 7a-b and 8a-b) depict the vertical upright updraft with low-level reflectivity maxima in close proximity to the maximum plume height. The application of buoyancy-generated vortex concepts to the two forest fires presented here has led to the WSR$88 \mathrm{D}$ observation of upwind transverse vortices and BSCP. Two distinct protrusions were identified on the upwind side of the Cedar Fire plume signaling climbing

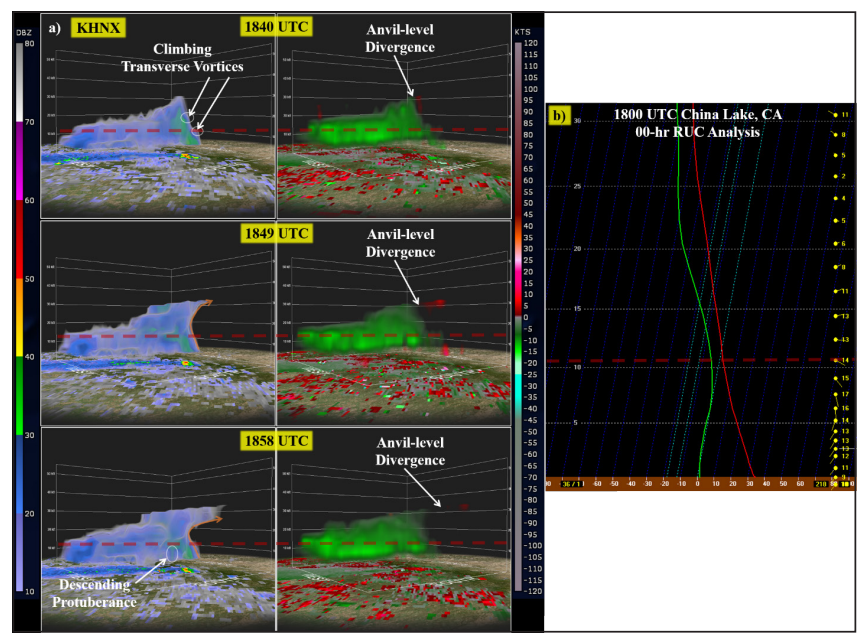

Figure 7. (a) 1840 to 1858 UTC KHNX base reflectivity (dBZ) and velocity (kt) volumetric depictions from GR2 Analyst for the Cedar Fire in south-central California on 19 August 2016. White transparent circles on upper left reflectivity image (1840 UTC) depict climbing transverse vortices on upwind side of the updraft. Orange arrow on the 1849 UTC reflectivity image highlights the developing stages of a BSCP, with longer orange arrow at 1858 UTC depicting a more fully developed BSCP as velocity analysis showed the presence of anvil-level divergence for all three times. (b) 00-hr RUC analysis for China Lake, California valid at 1800 UTC 19 August 2016 where solid red trace shows environmental temperature and solid green trace depicts environmental dewpoint, with wind barbs (kt) and digital readout displayed on the far right in yellow. White horizontal dashed lines with numeric values represent vertical height in $\mathrm{kft}$. Red dashed lines on both radar imagery (a) and forecast sounding (b) represent approximate height of the convective boundary layer. The white oval in 1858 UTC image depicts the descending protuberances possibly implying downward motion. transverse vortices (Fig. 7a). The Cedar Fire developed an enhanced BSCP signature 20 minutes later (Fig. 7a). A similar sequence occurred on the Hidden Pines Fire (Fig. 8a). Proximity soundings (Fig. $7 \mathrm{~b}$ and $8 \mathrm{~b}$ ) for the Cedar and Hidden Pines fires, respectively, clearly shows that the plumes rose through the top of the convective boundary layer and encountered weak ambient flow presumably near the equilibrium level (Wicker and Cantrell, 1996). Additional cases are needed to better associate the presence of the BSCP to the convective boundary layer, equilibrium levels, and ambient flow. It is our postulation that the radarobserved transverse vortices and BSCP agree with the Haines and Smith (1987) graphical depiction of a vortex ring distorted by ambient flow (Fig. 9). Indications of

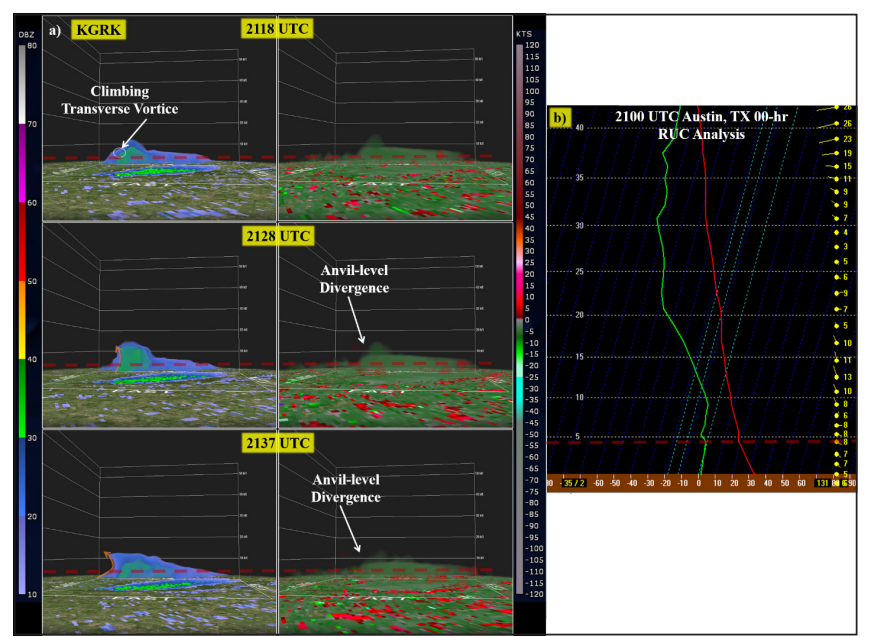

Figure 8. (a) 2118 to 2137 UTC KGRK base reflectivity (dBZ) and velocity (kt) volumetric depictions from GR2 Analyst for the Hidden Pines Fire in central Texas on 14 October 2015. White transparent circle on upper left reflectivity image (2118 UTC) depicts a climbing transverse vortice on the upwind side of the updraft. Orange arrow on the 2128 UTC reflectivity image highlights the developing stages of a BSCP, with longer orange arrow at 2137 UTC showing a more fully developed BSCP, while velocity analysis at both 2128 and 2137 UTC showed weak anvil-level divergence. (b) 00-hr RUC sounding analysis for Austin, Texas valid at 2100 UTC 14 October 2015, where solid red trace shows environmental temperature and solid green trace depicts environmental dewpoint, with wind barbs (kt) and digital readout displayed on the far right in yellow. White horizontal dashed lines with numeric values represent vertical height in kft. Red dashed lines on both radar imagery (a) and forecast sounding (b) represent approximate height of the convective boundary layer. 


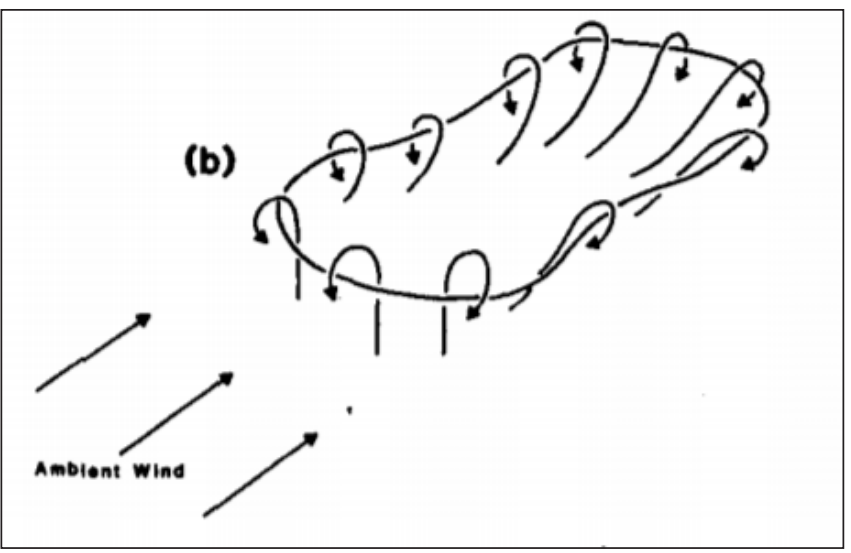

Figure 9. Taken from Haines and Smith 1987 that depicts a vortex ring distorted by ambient wind.

descending protuberances or lobes on the downwind side of the updraft were observed in the Cedar Fire (Fig. 7a); however, we are uncertain if this represents the downward component of the transverse vortices on the downwind side of the updraft, as in Fig. 3a from LC17. These protuberances are unlikely to be a separate descending branch.

\section{b. Environmental conditions and tactical implications}

Forthofer and Goodrick (2011) showed that the observation of climbing transverse vortices are not directly associated with "erratic fire behavior" but implies the presence of turbulence and the likelihood of increased combustion rates which have implications for changing fire behavior. Considering that the plume formation is a convective process, we note a potential ordered sequence of development, upwind transverse vortices and implied turbulence, and BSCP development. Similarly, we see this sequence as radar indications of increased combustion rates, implying the likelihood of increased fire intensity and transitory changes in fire behavior. These changes in fire behavior may include erratic spread as the buoyant updraft influences the inflow and outflow winds, thereby complicating the near-surface wind pattern resulting in the increased likelihood of non-steady state fire spread and less predictable tactical outcomes. Further study is needed to determine if upwind transverse vortices are potential pre-indicators of BSCP formation, and thus a predictive signature for possible erratic fire behavior.

For intense convective plumes, the radar-observed changes in maximum plume height is a direct indicator of changes in the updraft, and the updraft is related to convergence at the surface fire plume base (LC17). It is important for operational forecasters to understand that comparisons of maximum plume tops should be made relative to the convective boundary layer and not in terms of the absolute height of the plume. This is well known in the realm of severe moist convection by comparing the vertical extent of "low-topped" supercells to "traditional supercells" through the prism of the equilibrium level (Wicker and Cantrell 1996). As shown in Fig. 10, the maximum plume height of $3657 \mathrm{~m}$ does not necessarily imply that the Hidden Pines Fire was a less intense fire than the $9448 \mathrm{~m}$ plume height observed in the Cedar Fire when the depth of the convective boundary layer is taken into consideration. The operational takeaway is that a plume that exceeds the convective boundary layer is likely to have stronger fire generated inflow winds, and thus erratic spread.

\section{Conclusion}

Through plume analysis of WSR-88D reflectivity and derived echo top data in proximity to five wildland fires in Oklahoma, Texas, and California, we characterized both discrete multicell and intense convective plume modes. Our analyses showed that discrete multicell cases could be further subdivided into weak and strong multicells, in agreement with K09, with the primary discriminator being an almost continuous reflectivity plume signature downstream

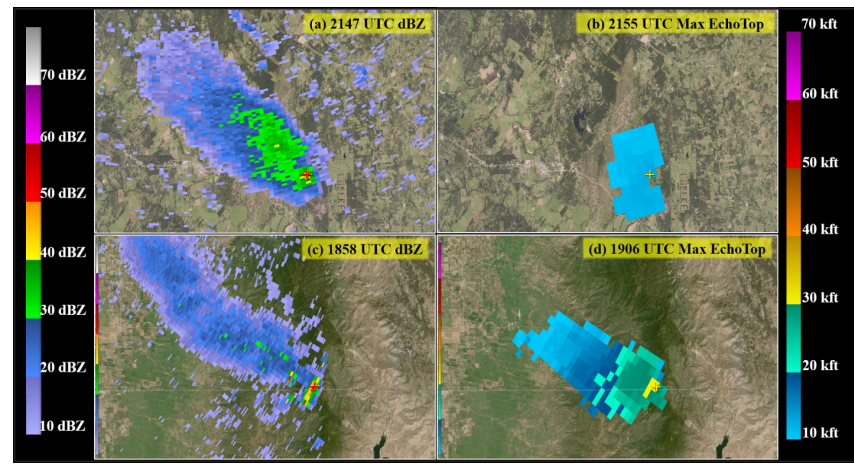

Figure 10. (a) KGRK base reflectivity (dBZ) and (b) maximum echo top (kft) for the Hidden Pines Fire (3657 $\mathrm{m}$ ) in central Texas on 14 October 2015. (c) KHNX base reflectivity (dBZ) and (d) maximum echo top (kft) for the Cedar Fire (9448 m) in south-central California on 19 August 2016. Yellow (maximum reflectivity, near updraft source) and red crosses (maximum echo top) are generally located in the same vicinity for both fires, highlighting how the low-level reflectivity maxima is often juxtaposed with the maximum echo top for plume dominated fires. 
of surface buoyancy source in weak multicell cases, whereas strong multicell cases maintain discrete thermal bubbles as the plume moves away from the fire. An important distinction is made between plume mode and fire intensity; weak multicell plume mode does not infer a fire with less intensity. Meanwhile, the intense convective plume mode is characterized by deep vertical updrafts with the main convective plume coincident with the main buoyancy source in response to a weak vertical wind profile, in agreement with K09. For such plume modes, our analyses identified key plume features to include thermal bubbles, vertical updrafts, plume scale transverse vortices, and BSCPs. Of most interest for intense convective plume mode was the identification of plume scale transverse vortices and the BSCP. The presence of the BSCP is thought to be the culmination of transverse vortices at the top of the convective boundary layer or equilibrium level and serve as an indication of a fully developed convective plume with a corresponding strong updraft.

In tactical firefighting, identifying changes in weather and fire behavior are at the forefront of priorities for firefighter safety. Even though it is difficult to provide specific impacts through radar analysis, our study linked radar signatures to plume mode in the wildfire environment. By monitoring and identifying changes in radar-based signatures and applying preexisting fire structure and behavior conceptual models to these signatures, it is proposed that meteorologists can derive useful fire environment intelligence for fire managers. Table 2 is a preliminary summary, based on limited data, serving as placeholder for future radar studies that may attempt to link plume mode radar signatures to environmental conditions and possible fire impacts. This summary can also serve as a template for future researchers and operational meteorologists to contextualize observations of plume mode and environmental conditions.

Tactical fire weather services provided by NWS forecasters are evolving. This evolution is most recently evidenced by the increased use of satellite datasets for fire notifications (Lindley et al. 2016). In addition, forecasters may consider using more rapid WSR88D VCPs, including Supplemental Adaptive IntraVolume Low-Level Scans (SAILS; Daniel et al. 2014), thereby increasing the temporal resolution of the lowest elevation scans. A new clear air mode scan strategy, VCP 35, runs at similar time intervals as precipitation modes and results in more frequent scans of convective plumes than VCP 31 and 32 (WDTD 2018). Expanded
Table 2. Summary of preliminary plume mode related radar signatures along with expected environmental conditions and possible impacts on wildland fires based on plume mode.

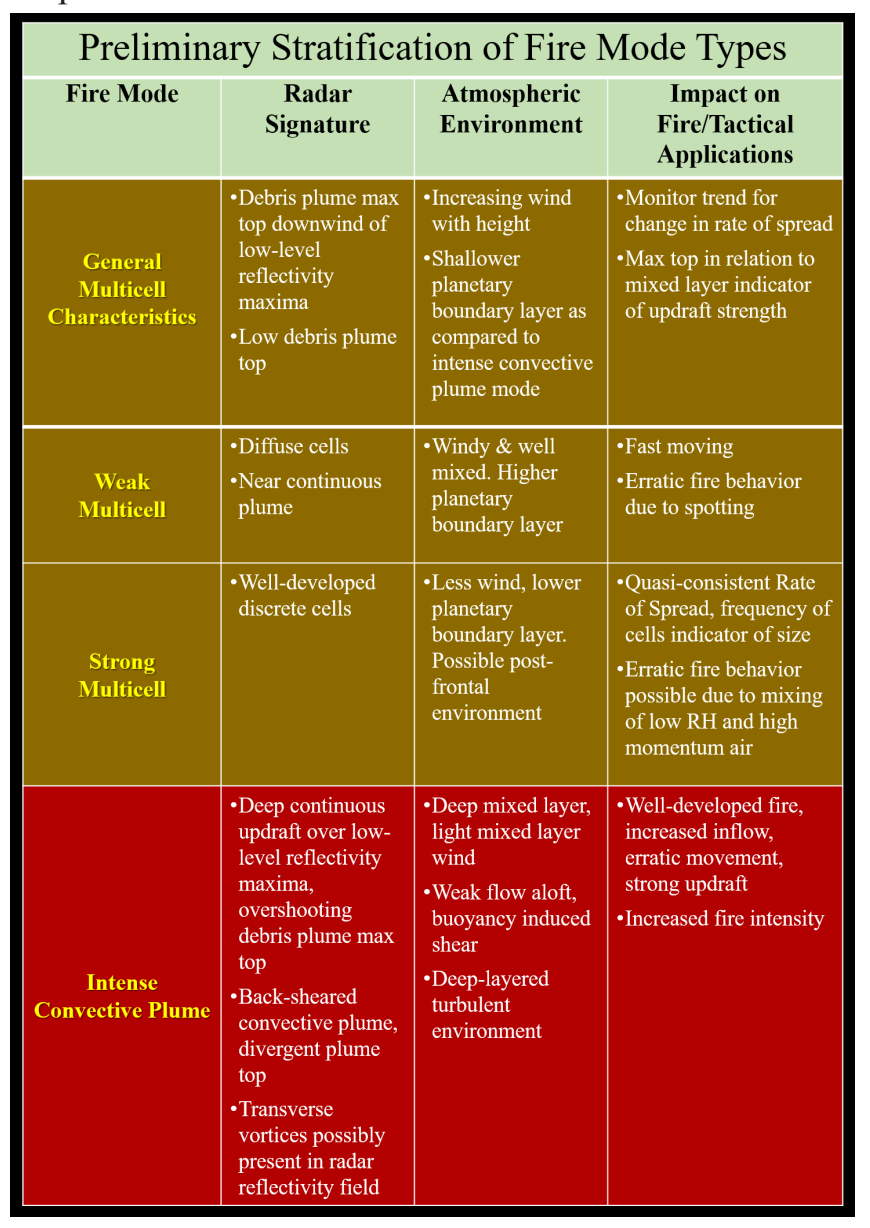

remote sensing strategies may serve as a prototype for future NWS fire warning paradigms (Lindley et al. 2018). Lareau et al. (2018) suggests the increased use of radar and satellite observations to provide heightened situational awareness of high impact wildfires. Although a variety of environmental conditions including topography, fuel type and suppression efforts can all lead to changes in wildland convective plume characteristics, meteorological remote sensing can provide valuable tactical information for increased firefighter safety.

Acknowledgments: The authors would like to thank both Scott Goodrick of the U. S. Forest Service's (USFS) Southern Research Station and Jason Forthofer of the USFS's Missoula Fire Science Lab for their enlightening discussions on transverse vortices, turbulence, and backsheared convective plume development. Additionally, 
great appreciation is also extended to Mr. Scott Watson of the Pleasant Hill Weather Forecast Office (WFO) for his assistance in creating Fig. 1. And finally, the authors wish to thank the Midland, Texas, Norman, Oklahoma, and Pleasant Hill, Missouri WFO management teams for their support and encouragement for seeing this project reach conclusion.

\section{REFERENCES}

Arizona State Fire Department, 2013: Yarnell Hill fire: Serious accident investigation report International Association of Wildland Fire, $25 \mathrm{pp}$. [Available online at https://docs.google.com/file/d/ 0B36DIycSgbzWSUtjNkl1Z2ROT0k/edit.]

Ashley, W. S., S. Strader, D. C. Dziubla, and A. Haberlie, 2015: Driving blind: Weather-related vision hazards and fatal motor vehicle crashes. Bull. Amer. Meteor. Soc., 96, 755-778, CrossRef.

Banta, R. M., L. D. Olivier, E. T. Holloway, R. A. Kropfli, B. W. Bartram, R. E. Cupp, and M. J. Post, 1992: Smokecolumn observations from two forest fires using Doppler LIDAR and Doppler radar. J. Appl. Meteor., 31, 13281349, CrossRef.

Bradshaw, L. S., J. E. Deeming, R. E. Burgan, and J. D. Cohen, 1983: The 1978 National Fire-Danger Rating System: Technical documentation. USDA Forest Service General Tech. Rep. INT-169, 49 pp. [Available online at www.fs.fed.us/rm/pubs int/int gtr169.pdf?]

Cheney, N. P., and G. A. V. Bary, 1969: The propagation of mass conflagrations in a standing eucalypt forest by the spotting process. In Mass Fire Symposium, Defense Standards Laboratory, Canberra, Australia, 10 12.

Clements, C.B., N.P. Lareau, D.E. Kingsmill, C.L. Bowers, C.P. Camacho, R. Bagley, and B. Davis, 2018: The Rapid Deployments to Wildfires Experiment (RaDFIRE): Observations from the Fire Zone. Bull. Amer. Meteor. Soc., 99, 2539- 2559, CrossRef.

Crum, T. D., and R. L. Alberty, 1993: The WSR-88D and the WSR-88D Operational Support Facility. Bull. Amer. Meteor. Soc., 74, 1669-1687, Crossref.

Daniel, A. E., J. N. Chrisman, S. D. Smith, and M. W. Miller, 2014: New WSR-88D Operational Techniques: Responding to recent Weather Events. 30th Conference on Environmental Information Processing Technologies, Atlanta, GA, Amer. Meteor. Soc., CrossRef.

Finney, M. A., and S. S. McAllister, 2018: Physical processes in wildland fire spread at fine scales. 25 April 2018 NWS Fire on the 5s presentation. Accessed 20 July 2018. [Available online at www.youtube.com/ watch?v=WxV0aRWHBWQ.]
Forthofer, J. M., and S. L. Goodrick, 2011: Review of vortices in wildland fire. J. Combust., 2011, 1-14, Crossref.

Glickman, T. S., Ed., 2000: Glossary of Meteorology. 2nd ed. Amer. Meteor. Soc., 855 pp.

Haines, D. A. and M. C. Smith, 1987: Three types of horizontal vortices observed in wildland mass and crown fires. J. Climate Appl. Meteor., 26(12), 1624-1637, CrossRef.

Jones, T. A. and S. A. Christopher, 2010: Satellite and radar remote sensing of Southern Plains grass fires: A case study. J. Appl. Meteor. Climatol., 49, 2133-2146, CrossRef.

Kiefer, M. T., Y-L. Lin, and J. J. Charney, 2008: A study of two-dimensional dry convective plume modes with variable critical level height. J. Atmos. Sci., 65, 448469, CrossRef.

, M. D. Parker, and J. J. Charney, 2009: Regimes of dry convection above wildfires: Idealized numerical simulations and dimensional analysis. J. Atmos. Sci., 66, 806-836, CrossRef.

Kumjian, M. R., 2013: Principles and applications of dual polarization weather radar. Part I: Description of the polarimetric radar variables. J. Operational Meteor., 1, 226-242, CrossRef.

Lareau, N. P., and C. B. Clements, 2016: Environmental controls on pyrocumulus and pyrocumulonimbus initiation and development. Atmos. Chem. Phys., 16, 4005-4022, Crossref.

, and C. B. Clements, 2017: The mean and turbulent properties of a wildfire convective plume. J. Appl. Meteor. Climatol., 56 (8), 2289-2299, CrossRef. , N. J. Nauslar, and J. T. Abatzoglou, 2018: The Carr fire vortex: A case of pyrotornadogenesis? Geophysical Research Letters, 45, 13,107-13,115, CrossRef.

Lindley, T. T., J. James, K. Widelski, G. Skwira, B. LaMarre, and S. Cobb, 2006: Operational practices during the January 12, 2006, wildfires and frontal passage in west Texas. NOAA/NWS/SR Technical Attachment, SR/SSD 2006-02.

,A. R. Anderson, V. N. Mahale, T. S. Curl, W. E. Line, S. S. Lindstrom, and A. S. Bachmeier, 2016: Wildfire detection notifications for impact-based decision support services in Oklahoma using geostationary super rapid scan satellite imagery. J. Operational Meteor., 4 (14), 182-191, CrossRef.

, G. P. Murdoch, R. Heffernan, L. VanBussum, A. Gerard, and N. Nauslar, 2018: An impact-based decision support paradigm for National Weather Service forecast and warning services. 12th Symposium on Fire \& Forest Meteorology, Boise, ID, Amer. Meteor. Soc., CrossRef.

Linn, R., J. Reisner, J. J. Colman, and J. Winterkamp, 2002: Studying wildfire behavior using FIRETEC. International Journal of Wildland Fire, 11, 233-246, CrossRef. 
McCarthy, N., H. McGowan, A. Guyot, and A. Dowdy, 2018: Mobile X-Pol Radar: A new tool for investigating pyroconvection and associated wildfire feteorology. Bull. Amer. Meteor. Soc., 99, 1177-1195, CrossRef.

, A. Guyot, A. Dowdy, and H. McGowan, 2019: Wildfire and weather radar: A review. Journal of Geophysical Research: Atmospheres, 124, 266-286, CrossRef.

Mphale, K., M. Heron, and T. Verma, 2007: Effect of wildfireinduced thermal bubble on radio communication. Progress in Electromagnetics Research (PIER), 68, 197228, CrossRef.

Murdoch, G. P., T. T. Lindley, and C. J. Morris 2016: A Doppler radar and conceptual analysis of horizontal longitudinal vortex influencing the Bastrop Complex wildfire. J. Operational Meteor., 4 (12), 160-169, CrossRef.

NOAA, 2017: WSR-88D meteorological observations. Part C: WSR-88D products and algorithms. Federal Meteorological Handbook 11. Accessed 29 September 2018, $\quad$ www.ofcm.gov/publications/fmh/FMH11/ fmh11partC.pdf.

NOAA, 2018: NWS WSR-88D Level II data collection and distribution network information. Accessed 29 September 2018, www.roc.noaa.gov/WSR88D/Level II/Level2Info.aspx.

NWS, 2018: Impact-based decision support services. Accessed 29 September 2018, www.weather.gov/about/ idss.

Potter, B. E., and J. R. Hernandez, 2017: Downdraft outflows: climatological potential to influence fire behaviour. International Journal of Wildland Fire, 26, 685-692. [Available online at: www.fs.fed.us/pnw/pubs/ journals/pnw 2017 potter001.pdf].

Rogers, R. R., and W. O. Brown, 1997: Radar observations of a major industrial fire. Bull. Amer. Meteor. Soc., 78, 803-814, Crossref.

Rothermel, R. C., 1991: Predicting behavior and size of crown fires in the northern Rocky Mountains. USDA Forest Service, Research Paper INT-438, CrossRef.

Sardoy, N., J.-L. Consalvi, B. Porterie, and A. C. FernandezPello, 2007: Modeling transport and combustion of firebrands from burning trees. Combustion and Flame, 150(3):151-169, CrossRef.

Scott, J. H. and R. E. Burgan, 2005: Standard fire behavior fuel models: a comprehensive set for use with Rothermel's surface fire spread model. Gen. Tech. Rep. RMRSGTR-153. Fort Collins, CO: U.S. Department of Agriculture, Forest Service, Rocky Mountain Research Station, CrossRef.

Stull, R. B., 1988: An Introduction to Boundary Layer Meteorology. Kluwer Academic Publishers. p. 441.
WDTD, cited 2018: RDA/RPG Build 18 Training. Warning Decision Training Division, Norman, OK. [Available online at: training.weather.gov/wdtd/buildTraining/ build18/presentation/presentation.html].

WDTD, cited 2019: Radar Applications Course, Introduction to the WSR-88D System. Warning Decision Training Division, Norman, OK. [Available online at: https:// training.weather.gov/wdtd/courses/rac/index.php].

Werth, P., and Coauthors, 2016: Synthesis of knowledge of extreme fire behavior: Volume 2 for fire behavior specialists, researchers, and meteorologists. Gen. Tech. Rep. PNW-GTR-891. Portland, OR: U. S. Department of Agriculture, Forest Service, Pacific Northwest Research Station. 258 pp., CrossRef.

Wicker, L. J. and L. Cantrell, 1996: The role of vertical buoyancy distributions in miniature supercells. Preprints, 18th Conference on Severe Local Storms, San Francisco, CA, Amer. Meteor. Soc., 225-229. 